\title{
Tomato fertigation in an open ground
}

\author{
Omariy G. Chamurliev ${ }^{1}$, Aleksandr N. Sidorov ${ }^{1}$, Anatoly A. Kholod ${ }^{1}$, \\ Georgy O. Chamurliev², Natalya V. Bogomolova ${ }^{2}$ \\ ${ }^{1}$ Volgograd State Agricultural University, Volgograd, Russian Federation \\ ${ }^{2}$ Peoples' Friendship University of Russia, Moscow, Russian Federation \\ *Correspondent author: giorgostsamourlidis@mail.ru
}

\begin{abstract}
Obtaining high and stable yields of tomato with good consumer qualities in the open field has now become problematic due to the fact that hybrids and varieties of tomato of an intensive type place high demands on the presence of moisture and nutrients in the root-soil layer. The required level of soil moisture in combination with the introduction of calculated doses of mineral fertilizers during the growing season provides for obtaining the planned yields of vegetables, including tomato. The most important resource for the further development of agriculture in the Russian Federation is irrigated land. Volgograd region is one of the largest irrigated agricultural regions in Russia. Growing of almost all vegetables in the region is conducted on irrigated lands. The use of only one irrigation without the use of fertilizers will not have a positive impact on the growth, development and productivity of plants. Fertigation is the most effective and economical way of delivering nutrients to the plant root system and allows to get a higher yields than other methods of fertilizer application. In fertigation systems, the control of optimal concentrations of fertilizers is easily achieved, their ratio and these parameters can be controlled automatically. The purpose of this work was to study the comparative efficiency of ammonium nitrate, calcium nitrate and a combination of calcium nitrate and ammonium chloride for tomato fertigation in combination with non-root dressings of complex water-soluble fertilizers containing macro- and microelements in open feild on irrigated lighchestnut soil of dry steppe zone of chestnut soils in the Volgograd region. As a result, analysis of the use of mineral fertilizers for tomato fertigation in light chestnut soils of the Volgograd region was carried out. The positive effect of foliar dressing with microelements in the proposed dosages has been proven.
\end{abstract}

Key words: irrigation, open field, soil moistening, planned crop, plant productivity, saltpeter, dry steppe zone, tomato, fertigation, foliar application

\section{Article history:}

Received: 25 March 2019. Accepted: 30 September 2019.

\section{For citation:}

Chamurliev OG, Sidorov AN, Kholod AA, Chamurliev GO, Bogomolova NV. Tomato fertigation in an open ground. RUDN Journal of Agronomy and Animal Industries. 2019; 14(4):347-361. doi: 10.22363/2312-797X-2019-14-4-347-361

(C) Чамурлиев О.Г., Сидоров А.Н., Холод А.А., Чамурлиев Г.О., Богомолова Н.В., 2019.

(c) () This work is licensed under a Creative Commons Attribution 4.0 International License https://creativecommons.org/licenses/by/4.0/ 


\title{
Фертигация томата в открытом грунте
}

\author{
О.Г. Чамурлиев ${ }^{1}$, А.Н. Сидоров ${ }^{1}$, А.А. Холод ${ }^{1}$, \\ Г.О. Чамурлиев ${ }^{2 *}$, Н.В. Богомолова ${ }^{2}$ \\ ${ }^{1}$ Волгоградский государственный аграрный университет, \\ г. Волгоград, Российская Федерачия \\ ${ }^{2}$ Российский университет дружбы народов, \\ 2. Москва, Российская Федерация \\ *giorgostsamourlidis@mail.ru
}

\begin{abstract}
Аннотация. Современные сорта и гибриды возделываемые в открытом грунте очень требовательны к наличию влаги и питательных веществ в почве.

Исследовано применение фергетации для повышения устойчивости томатов на орошаемых землях.

Изучена сравнительная эффективность использования аммиачной селитры, кальциевой селитры (нитрата кальция) и комбинации кальциевой селитры и хлорида аммония для фертигации томата в сочетании с некорневыми подкормками комплексными водорастворимыми удобрениями, содержащими макро- и микроэлементы, в открытом грунте на орошаемой светло-каштановой почве сухостепной зоны каштановых почв Волгоградской области.

Проведен анализ использования минеральных удобрений для фертигации томата в условиях светло-каштановых почв Волгоградской области. Доказано положительное влияние листовых подкормок микроэлементами в предложенных дозировках.
\end{abstract}

Ключевые слова: орошение, открытый грунт, увлажнение почвы, планируемый урожай, продуктивность растений, селитра, сухостепная зона, томат, фертигация, листовые подкормки, Волгоградская область

\section{История статьи:}

Поступила в редакцию: 25 марта 2019 г. Принята к публикации: 30 сентября 2019 г.

\section{Для цитирования:}

Чамурлиев О.Г., Сидоров А.Н., Холод А.А., Чамурлиев Г.О., Богомолова Н.В. Фертигация томата в открытом грунте // Вестник Российского университета дружбы народов. Серия: Агрономия и животноводство. 2019. Т. 14. № 4. С. 347-361. doi: 10.22363/2312-797X-2019-14-4-347-361

\section{Introduction}

Tomato is one of the most popular vegetables, required by the population of the Russian Federation in a fresh form. Under favourable import conditions of the last 20 years, as well as growth of greenhouse production, fresh tomato fruits became more affordable in the off-seasonal period $[1,2]$.

However, obtaining high and stable tomato yields having good consumer qualities in an open feild has now become problematic as tomato hybrids and varieties and of intensive type require increased moisture and nutrient level in root layer of soil. The difficulty is that weak and underdeveloped root system of tomato seedlings have to grow a large vegetative mass in a short period of time which is possible only under optimal soil moisture and fertilizer conditions [3-5]. 
Irrigated cropland is the most important resource for further development of the rural economy of the Russian Federation. The Volgograd region is one of the largest regions of the country where irrigated agriculture is used. Practically, all vegetable cultivation in the region is carried out on irrigated lands [6-8].

In vegetable farms of the Volgograd region, great importance is attached to development of environmentally friendly technologies and technical means of irrigation including drip irrigation. This method allows to maintain a favorable water and air regime in soil without surface and soil runoff of irrigation water [9]. Moistening soil in combination with application of calculated doses of mineral fertilizers during the vegetative period ensures the planned yields in different vegetables including tomatoes. Based on maintaining ecological, economic, social balance and stability, one of the basic tasks of irrigated agriculture is to use every cubic meter of irrigation water most effectively. Furthermore, it is reasonable to use irrigated croplands for the most valuable, highly profitable crops, among which is tomato. Plant water consumption and mineral nutrition is closely interconnected [10].

Application of only one irrigation without fertilizers does not show a positive effect on plant growth, development and productivity.

Fertigation is the most effective and economical way to increase nutrient availability to plant root system and results in higher yields compared to other methods. Control of optimal fertilizer concentration is easily accessible by the use of fertigation systems, where the parameters can be controlled automatically.

A complete refusal from the use of mineral fertilizers will inevitably lead to catastrophic reduction in food production. Therefore, the most correct is improvement of fertilizer application technology, their introduction in optimal doses and appropriate storage. When fertilizer application is uneven, some plants have excess amount of nutrients, while others lack minerals. This leads to unequal plant development and ripening, decreased yields and quality. Fertigation is free from these disadvantages, since it allows to add nutrients to root layer of the soil in a predetermined calculated dosage in all growth periods and development of tomato plants. The technology of fertigation can be improved by tomato leaf dressings with mimineral fertilizers [13-15].

The goal of this work was to study comparative efficiency of ammonium nitrate, calcium nitrate and a combination of calcium nitrate and ammonium chloride for tomato fertigation in combination with non-root dressings of complex water-soluble fertilizers containing macro- and microelements in open feild on irrigated lighchestnut soil of dry steppe zone of chestnut soils in the Volgograd region.

\section{Materials and methods}

Field experiments were conducted on light-chestnut soils in Gornaya Polyana Training Scientific and Production Center (Volgograd State Agrarian University) in 2016 2017. Tomato fertification in combination with various leaf dressings was studied.

The planting pattern is shown in Fig. 1. The number of planted plants per 1 ha was 28,000 . 


\section{Variants of field experiments for studing fertigation and leaf dressing effect (Gornaya Polyana)}

\begin{tabular}{|c|c|}
\hline № & Variant \\
\hline 1 & Ammonium nitrate fertigation \\
\hline 2 & $\begin{array}{l}\text { Ammonium nitrate fertigation } \\
\text { + NPK } 18: 18: 18 \text { leaf dressing + microelements in vegetative phase }(0.6 \% \text { solution, } 300 \mathrm{I} / \mathrm{ha}) \\
\text { + NPK } 10: 5: 40 \text { foliar dressing + microelements in the flowering-fruiting stage }(0.6 \% \text { solution, } 300 \mathrm{I} / \mathrm{ha})\end{array}$ \\
\hline 3 & Calcium nitrate fertigation \\
\hline 4 & $\begin{array}{l}\text { Calcium nitrate fertigation } \\
+ \text { NPK } 18: 18: 18 \text { leaf dressing + microelements in vegetative phase }(0.6 \% \text { solution, } 300 \mathrm{l} / \mathrm{ha}) \\
+ \text { NPK } 10: 5: 40 \text { foliar dressing + microelements in the flowering-fruiting stage }(0.6 \% \text { solution, } 300 \mathrm{I} / \mathrm{ha})\end{array}$ \\
\hline 5 & $\begin{array}{l}\text { Calcium nitrate fertigation before flowering-fruiting phase ( } 1-4 \text { fertigations })+ \text { calcium nitrate and potas- } \\
\text { sium chloride fertigation from flowering-fruiting phase }\left(12.7 \mathrm{kgCl} / \mathrm{ha}, 16.9 \mathrm{~kg} \mathrm{~K} \mathrm{O}_{2} \mathrm{O}\right)(5-6 \text { fertigations })\end{array}$ \\
\hline 6 & $\begin{array}{l}\text { Calcium nitrate fertigation before flowering-fruiting phase (1-4 fertigations) + calcium nitrate and potas- } \\
\text { sium chloride fertigation from flowering-fruiting phase }\left(12.7 \mathrm{kgCl} / \mathrm{ha}, 16.9 \mathrm{~kg} \mathrm{~K} \mathrm{~K}_{2} \mathrm{O}\right)(5-6 \text { fertigations }) \\
\text { + NPK } 18: 18: 18 \text { leaf dressing + microelements in vegetative phase }(0.6 \% \text { solution, } 300 \mathrm{l} / \mathrm{ha}) \\
\text { + NPK } 10: 5: 40 \text { foliar dressing + microelements in the flowering-fruiting stage }(0.6 \% \text { solution, } 300 \mathrm{l} / \mathrm{ha})\end{array}$ \\
\hline
\end{tabular}

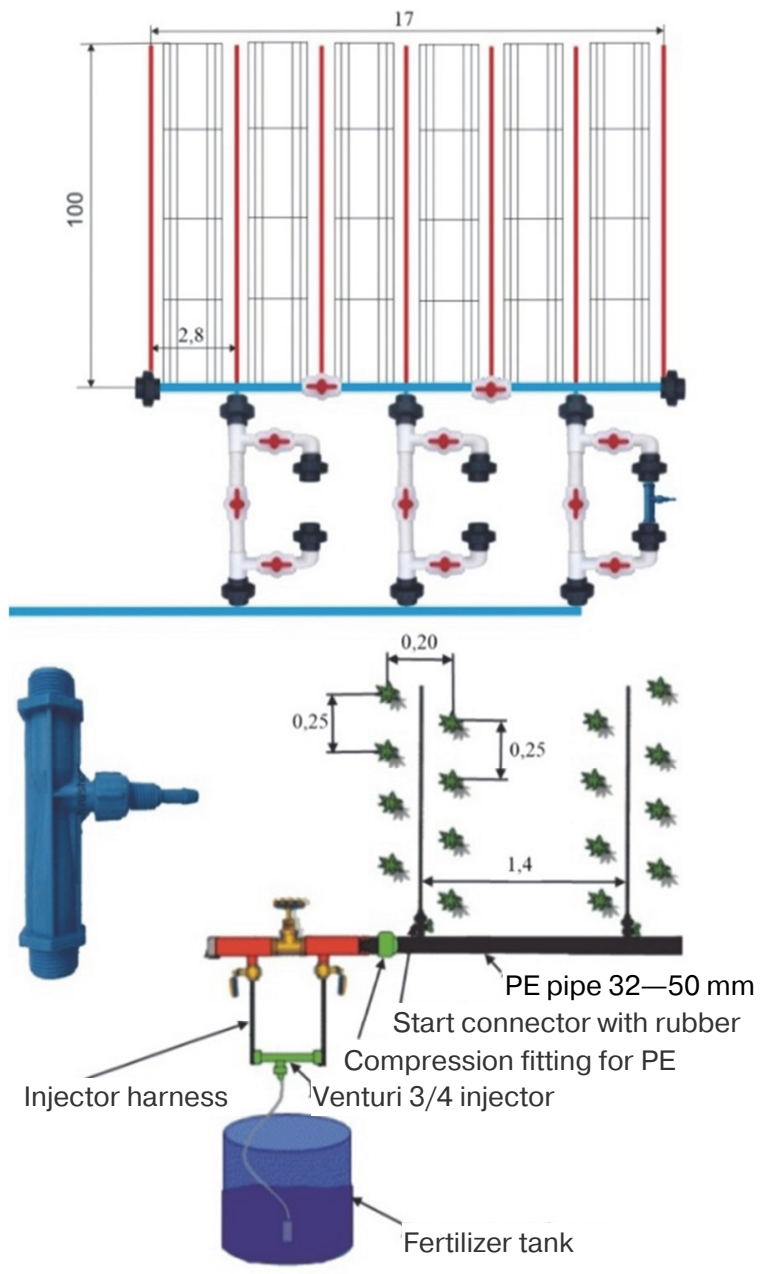

Fig. 1. Schematic diagram of drip irrigation system for tomato field experiment in Gornaya Polyana Center 
A unique drip irrigation system was used for tomato irrigatation. Irrigation was carried out to maintain pre-irrigation soil moisture in active layer at the level of $80 \% \mathrm{FC}$. Soil moisture was determined by thermostat-weight method, and also controlled using tensiometers [11].

Podarochny tomato variety was planted after safflower (Asteraceae) belonging to oil crops.

After harvesting safflower in August, stubble peeling followed by subsequent chisel tillage at $0.38 \ldots 0.40 \mathrm{~m}$ and real tillage at $0.20 \ldots 0.22 \mathrm{~m}$ was carried out.

Harrowing, weed cultivation and pre-sowing cultivation with local application of complex Azofoska mineral fertilizer (16.16.16) at a dose of $200 \mathrm{~kg} / \mathrm{ha}, 1.4 \mathrm{~kg} / \mathrm{plot}$ were carried out before seedling planting.

Schedule for Podarochny tomato fertification in field experiment:

1) seedling transplanting — 19 May

2) the first fertigation-June 1;

3) the second fertigation - June 9;

4) foliar dressing in tomato vegetative phase - 13 June;

5) the third fertigation - June 14;

6) the fourth fertigation - June 20;

7) foliar dressing in flowering - fruit formation stage — June 27;

8) the fifth fertigation - June 28;

9) the sixth fertigation - July 4.

\section{Results and discussion}

Planting seedlings in open ground was carried out in the second decade of May. During the week, the seedlings were taking root. Both pre-planting and post-planting irrigation were carried out with $80 \ldots 100 \mathrm{~m}^{3} /$ ha rate. $12 . .16$ days later, well developed tomato plants formed flower buds in some variants, and flowering stage was fixed in the second decade of June for all the variants.

Thus, period from planting to flowering was $36 . . .37$ days according to the variants. Period from flowering to fruit formation lasted $7 \ldots 8$ days. Period from fruit formation to full ripeness of fruits was from 42 to 44 days. The number of harvesting held was five.

The last harvest date was on 5 September. After completing vegetative irrigation of tomato plants they remained in good condition in the end of the second decade of September. Moreover, they actively flowered, carried fruits and formed a meaningful yields of green, brown and red fruits. Hence, duration of vegetative period in the studied tomato varieties can be conditionaly accepted at an average of 110 days.

Data on these indicators are shown in table 2.

Table 2

Dates of tomato phenological phases

\begin{tabular}{|l|c|c|c|c|c|c|}
\hline \multirow{2}{*}{ Variant } & \multicolumn{5}{|c|}{ Main phenological phases } \\
\cline { 2 - 7 } & $\begin{array}{c}\text { Trans- } \\
\text { planting }\end{array}$ & $\begin{array}{c}\text { Flower bud } \\
\text { formation }\end{array}$ & $\begin{array}{c}\text { Beginning } \\
\text { of flowering }\end{array}$ & Fruiting & $\begin{array}{c}\text { Beginning } \\
\text { of ripening }\end{array}$ & $\begin{array}{c}\text { Mass } \\
\text { ripening }\end{array}$ \\
\hline 1. Ammonium nitrate & 19 May & 19 June & 26 June & 4 July & 23 July & 15 August \\
\hline 3. Calcium nitrate & 19 May & 18 June & 25 June & 3 July & 23 July & 16 August \\
\hline $\begin{array}{l}\text { 5. Calcium nitrate + } \\
\text { potassium chloride }\end{array}$ & 19 May & 19 June & 25 June & 2 July & 22 July & 15 August \\
\hline
\end{tabular}


2 manual weeding and 6 intercultural cultivations were carried out during the vegetation period. To protect tomato plants from harmful pathogens, chemical treatments with fungicides and insecticides were carried out.

In order to maintain $80 \%$ FC pre-irrigation moisture content in $0.5 \mathrm{~m}$ soil layer, tomato seedlings were applied with 34 irrigation treatments with a total irrigation rate of $4200 \mathrm{~m}^{3} /$ ha (table 3 ) during the growing season. The amount of precipitation was $143 \mathrm{~mm}$ or $1430 \mathrm{~m}^{3} /$ ha for growing season. The use of soil moisture by tomato plants was $213 \ldots 276 \mathrm{~m}^{3} / \mathrm{ha}$.

Table 3

Influence of fertigation and foliar dressing on water consumption in Podarochny tomato (2016-2017)

\begin{tabular}{|c|c|c|c|c|c|c|c|}
\hline \multirow[t]{2}{*}{ Variant } & $\begin{array}{c}\text { Precipi- } \\
\text { tation }\end{array}$ & $\begin{array}{l}\text { Irrigation } \\
\text { rate }\end{array}$ & $\begin{array}{l}\text { Water con- } \\
\text { sumption }\end{array}$ & $\Sigma$ & \multirow{2}{*}{$\begin{array}{c}\text { Gross } \\
\text { yield, t/ha }\end{array}$} & \multirow{2}{*}{$\begin{array}{c}\text { Index of water } \\
\text { consumption, } \\
\mathrm{m}^{3} / \mathrm{t}\end{array}$} & \multirow{2}{*}{$\begin{array}{l}\text { Water use } \\
\text { efficiency, } \\
\mathrm{kg} / \mathrm{ha} / \mathrm{mm}\end{array}$} \\
\hline & \multicolumn{4}{|c|}{$\mathrm{m}^{3} / \mathrm{ha}$} & & & \\
\hline 1 & \multirow{6}{*}{1430} & \multirow{6}{*}{4200} & 276 & 5906 & 68.5 & 86.2 & 115.9 \\
\hline 2 & & & 264 & 5894 & 69.2 & 85.2 & 117.4 \\
\hline 3 & & & 213 & 5843 & 71.6 & 81.6 & 122.5 \\
\hline 4 & & & 227 & 5857 & 72.8 & 80.5 & 124.3 \\
\hline 5 & & & 245 & 5875 & 89.4 & 65.7 & 152.2 \\
\hline 6 & & & 251 & 5881 & 103.6 & 56.8 & 176.2 \\
\hline
\end{tabular}

Table 4

The effect of fertilization on yield structure of tomato cv. Podarochny (2016-2017)

\begin{tabular}{|c|c|c|c|c|c|}
\hline Variant & $\begin{array}{c}\text { Average number } \\
\text { of fruits per plant }\end{array}$ & $\begin{array}{c}\text { Average fruit } \\
\text { weight, } g\end{array}$ & $\begin{array}{c}\text { Standard fruit } \\
\text { yield, } \mathrm{t} / \mathrm{ha}\end{array}$ & $\begin{array}{c}\text { Non-standard } \\
\text { fruit yield, t/ha }\end{array}$ & $\begin{array}{c}\text { Waste (diseased } \\
\text { fruits), \% }\end{array}$ \\
\hline 1 & 20 & 122 & 64.4 & 4.1 & 6 \\
\hline 2 & 22 & 112 & 65.0 & 4.2 & 6 \\
\hline 3 & 23 & 111 & 68.0 & 3.6 & 5 \\
\hline 4 & 23 & 113 & 69.9 & 2.9 & 4 \\
\hline 5 & 24 & 133 & 84.9 & 4.5 & 5 \\
\hline 6 & 26 & 142 & 99.4 & 4.2 & 4 \\
\hline
\end{tabular}

$\mathrm{LSD}_{05}-14.16$.

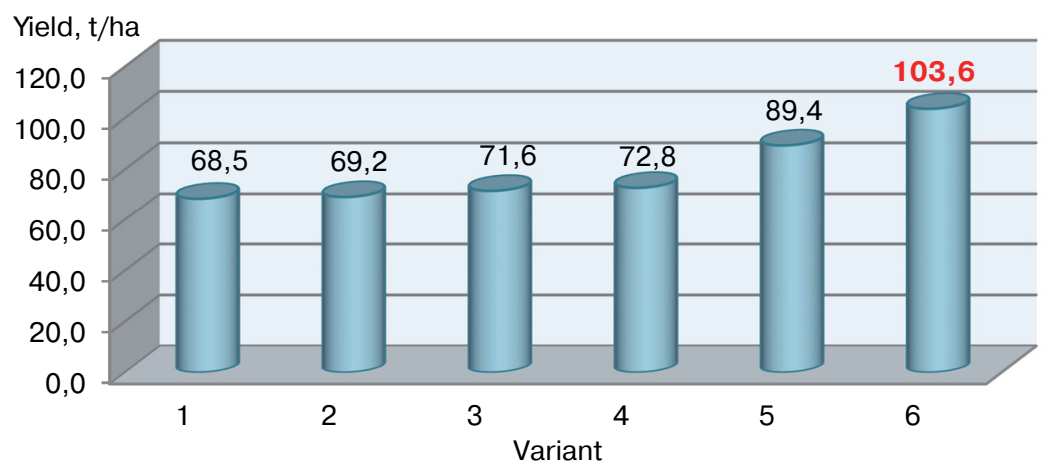

Fig. 2. Tomato yield, t/ha (2016-2017) 
An analysis of the harvested tomato structure shows that minimum number of fruits per plant (20) with an average mass of $122 \mathrm{~g}$ was formed in the first variant with ammonium nitrate without foliar treatments. The maximum values (26 fruits, $142 \mathrm{~g}$ ) were obtained in the last variant, where calcium nitrate and ammonium chloride in combination with foliar dressings were used for fertigation.

The second to fifth experimental variants occupied an intermediate position, where the average number of fruits on the plant ranged from 22 to 24, and their mass ranged from 111 to $133 \mathrm{~g}$ (Table 4).

As a result, the total yield of standard and non-standard fruits was also the largest in the sixth variant — 103.6 t/ha, in the fifth variant it was $14.2 \mathrm{t} / \mathrm{ha}$ less, $72.8 \mathrm{t} / \mathrm{ha}$ was in the fourth variant, and the lowest yield $(68.5 \mathrm{t} / \mathrm{ha})$ was recorded in the first variant, which was $35.1 \mathrm{t} / \mathrm{ha}(33.8 \%)$ less compared to the sixth variant.

\section{Conclusions}

The obtained results confirm conclusions about the significant advantages of using calcium nitrate for tomato fertigation compared to ammonium nitrate. Moreover, the experiments demonstrated that additional application of chlorides and foliar dressings with complex water-soluble fertilizers in fertilization program gave better results. Thus, it resulted in not only tomato yield increase, but also improvement in such quality indicators, as content of soluble solids and keeping quality of fruit.

The results of the study also indicate that the studied tomato fertilization programs did not showed any negative effect on salt content and composition of exchange cations in light-chestnut soil.

\section{Введение}

Томат является одним из самых востребованных овощей, потребляемых населением Российской Федерации в свежем виде. В сложившихся за последние 20 лет условиях относительно свободного импорта, а также роста тепличного производства, свежие плоды томата стали более доступными во внесезонное время $[1,2]$.

Вместе с тем получение высоких и стабильных урожаев томата с хорошими потребительскими качествами в открытом грунте в настоящее время стало проблематичным вследствие того, что гибриды и сорта томата интенсивного типа предъявляют повышенные требования к наличию влаги и питательных веществ в корнеобитаемом слое почвы. Сложность в том, что при слаборазвитой корневой системе растения томата должны за короткий промежуток времени нарастить большую вегетативную массу, что возможно только при оптимальной влажности почвы и активном потреблении необходимого количества элементов минерального питания [3-5].

Важнейшим ресурсом дальнейшего развития сельского хозяйства Российской Федерации являются орошаемые земли. Волгоградская область - один из крупных регионов орошаемого земледелия нашей страны. Практически все овощеводство в области ведется на поливных землях [6-8].

В овощеводческих хозяйствах Волгоградской области большое значение придается освоению экологически безопасных технологий и технических средств полива, к которым относится капельное орошение. Этот способ позволяет поддерживать в почве благоприятный водно-воздушный режим без поверхностного 
и внутрипочвенного стоков оросительной воды [9]. Необходимый уровень увлажнения почвы в сочетании с внесением расчетных доз минеральных удобрений в течение вегетационного периода обеспечивает получение планируемых урожаев овощей, в т.ч. и томата. Исходя из соображений поддержания экологического, экономического, социального равновесия и стабильности, одна из основных задач орошаемого земледелия состоит в том, чтобы использовать каждый кубический метр оросительной воды, расходуемой на полив сельскохозяйственных культур, наиболее эффективно. Наряду с этим использовать орошаемые земли целесообразно, прежде всего, под ценные, высокорентабельные культуры, к числу которых относится томат. Водопотребление растений и минеральное питание тесно взаимосвязаны [10].

Применение только одного орошения без применения удобрений не окажет положительного влияния на рост, развитие и продуктивность растений.

Фертигация является наиболее эффективным и экономичным способом доставки питательных веществ к корневой системе растений и позволяет получать более высокий урожай по сравнению с другими способами внесения удобрений. В системах фертигации легко достигается управление оптимальными концентрациями удобрений, их соотношением и эти параметры могут контролироваться в автоматическом режиме $[11,12]$.

Полный отказ от применения минеральных удобрений, который некоторые предлагают в качестве одного из путей развития сельского хозяйства, неизбежно приведет к катастрофическому сокращению производства продовольствия. Поэтому более правильным является коренное улучшение технологии использования минеральных удобрений, внесение их в оптимальных дозах и соотношениях, правильное хранение. При неравномерном их внесении одни растения получают избыточное, а другие - недостаточное количество питательных веществ. Это приводит к неодинаковым темпам развития и созревания растений, снижению урожая и качества продукции. Фертигация свободна от этих недостатков, поскольку позволяет вносить питательные вещества в корнеобитаемый слой почвы в заданной расчетной дозировке во все периоды роста и развития растений томата. Технологию фертигации можно усовершенствовать за счет проведения листовых (некорневых) подкормок томата растворами минеральных удобрений [13 - 15].

Цель данной работы заключалась в изучении сравнительной эффективности использования аммиачной селитры, кальциевой селитры (нитрата кальция) и комбинации кальциевой селитры и хлорида аммония для фертигации томата в совокупности с некорневыми подкормками комплексными водорастворимыми удобрениями, содержащими макро- и микроэлементы, в открытом грунте на орошаемой светло-каштановой почве сухостепной зоны каштановых почв Волгоградской области.

\section{Материалы и методы}

В 2016-2017 г. на светло-каштановой почве в УНПЦ «Горная Поляна» Волгоградского государственного аграрного университета были проведены полевые опыты по изучению фертигации томата в открытом грунте в сочетании с листовыми подкормками NPK и микроэлементами, включающие варианты, приведенные в табл. 1.

Схема посадки изображена на рис. 1. Количество высаженных растений на 1 га составило 28000 шт. 
Варианты полевого опыта по изучению эффективности фертигации и некорневых подкормок томата в открытом грунте УНПЦ “Горная Поляна»

\begin{tabular}{|c|c|}
\hline № & Варианты полевого опыта \\
\hline 1 & Фертигация аммиачной селитрой \\
\hline 2 & $\begin{array}{l}\text { Фертигация аммиачной селитрой } \\
\text { + листовая подкормка NPK } 18: 18: 18 \text { + микроэлементы в фазу активного роста (0,6\% раствор, } \\
300 \text { л/га) } \\
\text { + листовая подкормка NPK 10:5:40 + микроэлементы в фазу цветения - плодообразования } \\
\text { (0,6\% раствор, } 300 \text { л/га) }\end{array}$ \\
\hline 3 & Фертигация нитратом кальция \\
\hline 4 & $\begin{array}{l}\text { Фертигация нитратом кальция } \\
+ \text { листовая подкормка NPK 18:18:18+ микроэлементы в фазу активного роста (0,6\% раствор, } \\
300 \text { л/га) } \\
\text { + листовая подкормка NPK 10:5:40 + микроэлементы в фазу цветения-плодообразования } \\
\text { (0,6\% раствор, } 300 \text { л/га) }\end{array}$ \\
\hline 5 & $\begin{array}{l}\text { Фертигация нитратом кальция до фазы цветения - образования плодов (1-4 фертигации) } \\
\text { + фертигация нитратом кальция и хлоридом калия, начиная с фазы цветения - образования } \\
\text { плодов }(12,7 \text { кг Cl/га, } 16,9 \text { кг Кㅇ) (5-6 фертигации) }\end{array}$ \\
\hline 6 & $\begin{array}{l}\text { Фертигация нитратом кальция до фазы цветения - образования плодов (1-4 фертигации) } \\
\text { + фертигация нитратом кальция и хлоридом калия, начиная с фазы цветения - образования } \\
\text { плодов (12,7 кг СІ/га, 16,9 кг Кㅇ) (5-6 фертигации) } \\
\text { + листовая подкормка NPK } 18: 18: 18 \text { + микроэлементы в фазу активного роста (0,6\% раствор, } \\
300 \text { л/га) } \\
\text { + листовая подкормка NPK 10:5:40 + микроэлементы в фазу цветения-плодообразования } \\
\text { (0,6\% раствор, } 300 \text { л/га) }\end{array}$ \\
\hline
\end{tabular}

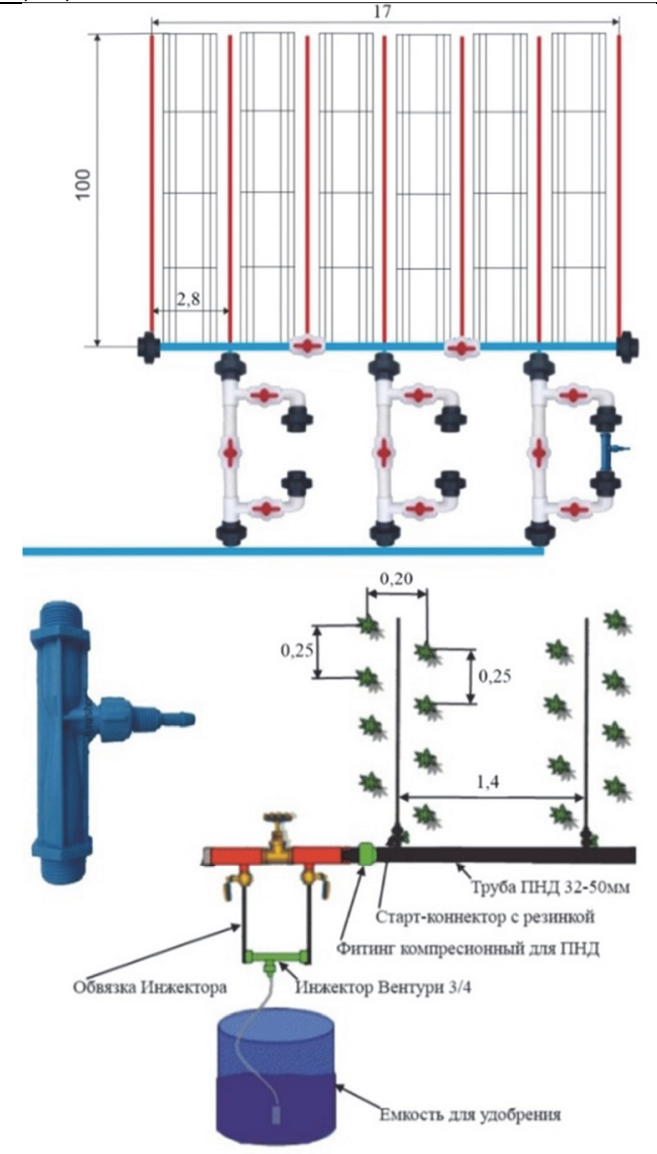

Рис. 1. Принципиальная схема системы капельного орошения в полевом опыте с томатом в УНПЦ «Горная Поляна» 
Для полива томата использовалась специально смонтированная система капельного орошения. Поливы проводили для поддержания предполивного порога влажности почвы в активном слое на уровне 80\% НВ. Влажность почвы определяли термостатно-весовым методом, а также контролировали при помощи тензиометров [11].

Исследуемый сорт томата Подарочный высаживали после предшественника сафлор красильный, который относится к семейству сложноцветные, по характеру использования - к группе масличных технических культур.

После уборки сафлора красильного в августе проводили лущение стерни с последующей вспашкой чизельно-отвальными рабочими органами Ранчо на глубину рыхления 0,38...0,40 м с оборотом пласта на глубину 0,20...0,22 м.

Весной последовательно проводили покровное боронование, культивацию по мере отрастания сорняков и предпосевную культивацию перед высадкой рассады с локальным внесением комплексного минерального удобрения азофоска 16.16.16 дозой 200 кг/га, 1,4 кг/делянку.

График проведения фертигаций томата Подарочный в полевом опыте:

1) высадка рассады - 19 мая;

2) первая фертигация - 1 июня;

3) вторая фертигация - 9 июня;

4) листовая подкормка в фазу активного роста томата - 13 июня;

5) третья фертигация - 14 июня;

6) четвертая фертигация - 20 июня;

7) листовая подкормка в фазу цветения-плодообразования - 27 июня;

8) пятая фертигация - 28 июня;

9) шестая фертигация - 4 июля.

\section{Результаты исследований}

Высадка рассады в открытый грунт проводилась во второй декаде мая. В течение недели рассада приживалась. Проводились как допосадочный, так и после-

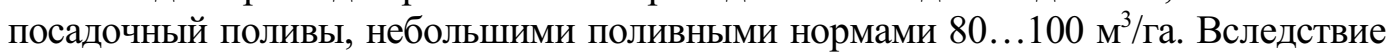
хорошего развития растений уже через $12 \ldots 16$ дней было отмечено образование цветочных кистей по некоторым вариантам, а фаза цветения во второй декаде июня зафиксирована на всех вариантах.

Таким образом, период от посадки до цветения по вариантам составил 36...37 дней. Период от цветения до плодообразования продолжался от 7 до 8 дней. Бурая спелость плодов отмечена через $64 . .65$ дней. Период от плодообразования до полной спелости составил по сортам от 42 до 44 дней. Количество проведенных сборов - пять.

Дата последнего сбора - 5 сентября. После завершения вегетационных поливов растения томатов и в конце второй декады сентября оставались в хорошем состоянии, активно цвели, плодоносили и формировали значительный урожай плодов: зеленых, бурых и красных. Продолжительность вегетационного периода изучаемых сортов томата, таким образом, может быть условно принята в среднем равной 110 дням.

Данные об этих показателях приведены в табл. 2. 
Даты наступления фенологических фаз развития томата

\begin{tabular}{|l|c|c|c|c|c|c|}
\hline \multirow{2}{*}{ Вариант опыта } & \multicolumn{5}{|c|}{ Основные фенологические фазы томата } \\
\cline { 2 - 7 } & $\begin{array}{c}\text { Высадка } \\
\text { рассады }\end{array}$ & $\begin{array}{c}\text { Образова- } \\
\text { ние бутонов }\end{array}$ & $\begin{array}{c}\text { Начало } \\
\text { цветения }\end{array}$ & $\begin{array}{c}\text { Плодообра- } \\
\text { зование }\end{array}$ & $\begin{array}{c}\text { Начало } \\
\text { созревания }\end{array}$ & $\begin{array}{c}\text { Массовое } \\
\text { созревание }\end{array}$ \\
\hline $\begin{array}{c}\text { 1. Аммиачная } \\
\text { селитра }\end{array}$ & 19 мая & 19 июня & 26 июня & 4 июля & 23 июля & 15 августа \\
\hline 3. Нитрат кальция & 19 мая & 18 июня & 25 июня & 3 июля & 23 июля & 16 августа \\
\hline $\begin{array}{c}5 \text { Нитрат кальция } \\
\text { + хлорид калия }\end{array}$ & 19 мая & 19 июня & 25 июня & 2 июля & 22 июля & 15 августа \\
\hline
\end{tabular}

Влияние программ фертигации и некорневых подкормок на эффективность использования воды растениями сорта томата Подарочный (среднее за 2016-2017 гг.)

\begin{tabular}{|c|c|c|c|c|c|c|c|}
\hline \multirow[t]{2}{*}{$\begin{array}{c}\text { Вариант } \\
\text { опыта }\end{array}$} & $\begin{array}{l}\text { Атмосфер- } \\
\text { ные осадки }\end{array}$ & $\begin{array}{l}\text { Ороси- } \\
\text { тельная } \\
\text { норма }\end{array}$ & $\begin{array}{c}\text { Использован- } \\
\text { ная растени- } \\
\text { ями влага } \\
\text { из почвы }\end{array}$ & $\Sigma$ & \multirow[t]{2}{*}{$\begin{array}{c}\text { Общая } \\
\text { урожайност } \\
\text { ь плодов, } \\
\text { т/га }\end{array}$} & \multirow[t]{2}{*}{$\begin{array}{c}\text { Коэффицие } \\
\text { нт водопо- } \\
\text { требления, } \\
\text { м }^{3} / \text { т }\end{array}$} & \multirow[t]{2}{*}{$\begin{array}{l}\text { Эффективность } \\
\text { использования } \\
\text { воды, кг/га/мм }\end{array}$} \\
\hline & \multicolumn{4}{|c|}{ м³/га } & & & \\
\hline 1 & \multirow{6}{*}{1430} & \multirow{6}{*}{4200} & 276 & 5906 & 68,5 & 86,2 & 115,9 \\
\hline 2 & & & 264 & 5894 & 69,2 & 85,2 & 117,4 \\
\hline 3 & & & 213 & 5843 & 71,6 & 81,6 & 122,5 \\
\hline 4 & & & 227 & 5857 & 72,8 & 80,5 & 124,3 \\
\hline 5 & & & 245 & 5875 & 89,4 & 65,7 & 152,2 \\
\hline 6 & & & 251 & 5881 & 103,6 & 56,8 & 176,2 \\
\hline
\end{tabular}

За время вегетации проведены 2 ручные прополки и 6 междурядных культиваций. Для защиты растений томата от вредных патогенов осуществляли химические обработки фунгицидами против болезней и инсектицидами против вредителей.

Для поддержания предполивной влажности в расчетном слое почвы 0,5 м на уровне $80 \%$ НВ в течение вегетационного периода на посадках томата было проведено 34 полива общей оросительной нормой $4200 \mathrm{~m}^{3} /$ га (табл. 3). Приход влаги от осадков составил за вегетацию 143 мм или 1430 м³ $^{3}$ г. Использование запасов почвенной влаги растениями томата равнялось $213 \ldots 276 \mathrm{~m}^{3} /$ га.

Анализ структуры урожая томата свидетельствует о том, что минимальное количество плодов на кусте (20 шт.) со средней массой 122 г формировалось в первом варианте с фертигацией аммиачной селитрой без проведения некорневых подкормок. Максимальные же показатели (26 шт. и 142 г соответственно) были получены в последнем варианте, где для фертигации применялось сочетание кальциевой селитры и хлорида аммония и осуществлялись некорневые подкормки комплексными водорастворимыми удобрениями.

Варианты опыта со второго по пятый занимали промежуточное положение, где среднее количество плодов на кусте составляло от 22 до 24 шт., а их масса колебалась от 111 до 133 г. (табл. 4). 
Влияние минерального питания на структура урожая томата Подарочный (среднее за 2016-2017 гг.)

\begin{tabular}{|c|c|c|c|c|c|}
\hline $\begin{array}{c}\text { Вариант } \\
\text { опыта }\end{array}$ & $\begin{array}{c}\text { Среднее коли- } \\
\text { чество плодов } \\
\text { на кусте, шт. }\end{array}$ & $\begin{array}{c}\text { Средняя масса } \\
\text { плода, } г\end{array}$ & $\begin{array}{c}\text { Урожайность } \\
\text { стандартных } \\
\text { плодов, т/га }\end{array}$ & $\begin{array}{c}\text { Урожайность } \\
\text { нестандартных } \\
\text { плодов, т/га }\end{array}$ & $\begin{array}{c}\text { Отход (пораженные } \\
\text { болезнями плоды), } \\
\%\end{array}$ \\
\hline 1 & 20 & 122 & 64,4 & 4,1 & 6 \\
\hline 2 & 22 & 112 & 65,0 & 4,2 & 6 \\
\hline 3 & 23 & 111 & 68,0 & 3,6 & 5 \\
\hline 4 & 23 & 113 & 69,9 & 2,9 & 4 \\
\hline 5 & 24 & 133 & 84,9 & 4,5 & 4 \\
\hline 6 & 26 & 142 & 99,4 & 4,2 & 4 \\
\hline
\end{tabular}

$$
\mathrm{HCP}_{05}-14,16 \text {. }
$$

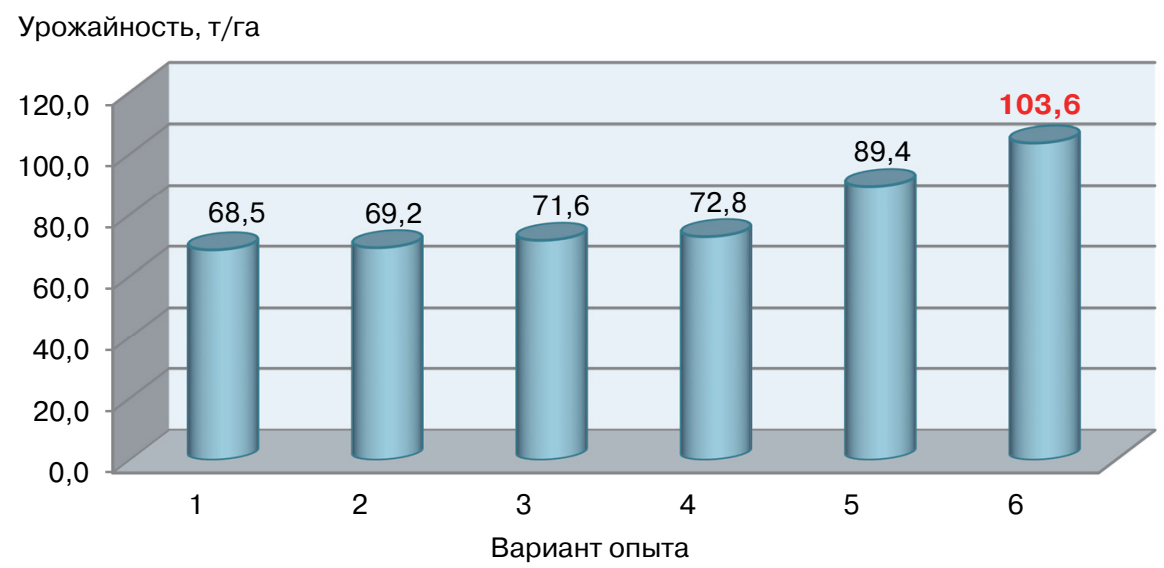

Рис. 2. Урожайность томата по вариантам опыта, т/га (среднее за 2016-2017 гг.)

В результате общая урожайность стандартных и нестандартных плодов также была наибольшей на шестом варианте 103,6 т/га, на пятом варианте на 14,2 т меньше, далее по урожайности стандартных плодов шел четвертый вариант 72,8 т/га, а самая низкая урожайность зафиксирована на первом варианте 68,5 т/га, что являлось на 35,1 т/га или на 33,8\% меньше по отношению к шестому варианту (рис. 2).

\section{Выводы}

Полученные результаты подтверждают выводы о значительных преимуществах при использовании для фертигации томата кальциевой селитры по сравнению с аммиачной селитрой в исследовании. Эксперименты к тому же продемонстрировали, что включение в программу фертигации хлоридов, а также некорневые подкормки комплексными водорастворимыми удобрениями дают еще более лучшие результаты. При этом наблюдается не только рост урожайности томата, но и улучшение таких качественных показателей, как содержание растворимых сухих веществ и лежкость плодов. 
Результаты исследований также свидетельствуют о том, что изученные системы питания томата, включающие внесение с фертигацией существенных количеств кальция и небольших количеств хлора, не оказывали какого-либо отрицательного влияния на содержание солей и состав обменных катионов в светло-каштановой почве.

\section{References}

1. Klimenko NN. Vegetable growing of South of Russia. Potato and vegetables. 2013; (8):2-5. (In Russ).

2. Khoroshkin AB. Fertilizing of vegetable crops in South of Russia. Potato and vegetables. 2017; (11):16-18. (In Russ).

3. Dolgusha D. Fertigation: fast and convenient. Vestnik ovoshchevoda. 2014; (6):12-14. (In Russ).

4. Rusan M. Fertigatsiya ovoshchnykh kul'tur pri kapel'nom oroshenii na Blizhnem Vostoke: Ispol'zovanie kontseptsii «4-kh pravil» primeneniya udobrenii [Vegetation of vegetable crops with drip irrigation in the Middle East: Using the concept of "4 rules" in fertilizer use]. Volgograd: IPNI Publ.; 2015. (In Russ). Available from: http://eeca-ru.ipni.net/article/EECARU-2282

5. Filin VI, Filin VV. Optimization of fertilizer system of vegetable crops in the Volgograd region. Proceedings of Nizhnevolzskiy agrouniversity complex: science and higher vocational education. 2011;(3):43-50. (In Russ).

6. Azaryeva II. Sovershenstvovanie tekhnologii kapel'nogo orosheniya tomatov na svetlo-kashtanovykh pochvakh Nizhnego Povolzh'ya [Improvement of the technology of drip tomato irrigation on light chestnut soils of the Lower Volga] [Dissertation] Volgograd; 2010. (In Russ).

7. Borodychev VV. Sovremennye tekhnologii kapel'nogo orosheniya ovoshchnykh kul'tur: nauchnoe izdanie [Modern technologies of drip irrigation of vegetable crops: scientific publication]. Kolomna: Raduga Publ.; 2010. (In Russ).

8. Komarov VN, Kiseleva NN, Vorontsova AI. Application of technological methods of tomato cultivation during drip irrigation. In: Melioratsiya i problem vosstanovleniya sel"skogo khozyaistva $v$ Rossii [Recovery and problems of restoration of agriculture in Russia]. Moscow: Pryanishnikov Research Institute of Agrochemistry Publ.; 2013. p. 163-166. (In Russ).

9. Ovchinnikov AS, Bocharnikov VS, Bocharnikova OV, Meshcheryakov MP. Innovative technologies for irrigation of vegetable crops. Proceedings of Nizhnevolzskiy agrouniversity complex: science and higher vocational education. 2011; (4):13-17. (In Russ).

10. Grigorov MS. Tomato productivity under drip irrigation in light chestnut soils of the Volgograd Region. Proceedings of Nizhnevolzskiy agrouniversity complex: science and higher vocational education. 2014; (2):22-27. (In Russ).

11. Nosov VV, Pleskachev YN, Filin VI, Chamurliev OG, Borisenko IB, Kholod AA, Sidorov AN. Tomato fertigation with calcium and chlorine-containing fertilizers and non-root top dressing with complex water-soluble fertilizers on light chestnut soil of the Volgograd region. IPNI Newsletter in Russian. 2017; (3):7-12. (In Russ).

12. Filin VI. Crop programming: from idea to theory and technology of agricultural crops. Proceedings of Nizhnevolzskiy agrouniversity complex: science and higher vocational education. 2014; (3):26-36. (In Russ).

13. Avdeev YI. Technology of tomatoes in the open ground of the Astrakhan region. Potato and vegetables. 2014; (5):7-9. (In Russ).

14. Gil LS, Pashkovsky AI, Sulima LT. Sovremennoe ovoshchevodstvo zakrytogo i otkrytogo grunta. Prakticheskoe rukovodstvo [Modern vegetable growing in open and protective ground. A practical guide]. Zhitomir: Ruta; 2012. (In Russ). Available from: https://ua.b-ok2.org/book/3037453/300cb0

15. Grushanin AI, But NN. New varieties and hybrids of tomato for open ground of Kuban. Potato and vegetables. 2012; (3):19-20. (In Russ). 


\section{Библиографический список}

1. Клименко Н.Н. Овощеводство юга России // Картофель и овощи. 2013. № 8. С. 2-3.

2. Хорошкин А.Б. Удобрение овощных на юге России // Картофель и овощи. 2017. № 11. C. $16-18$.

3. Долгуша Д. Фертигация: быстро и удобно // Вестник овощевода. 2014. № 6. С. 12-14.

4. Русан М. Фертигация овощных культур при капельном орошении на Ближнем Востоке: Использование концепции «4-х правил» применения удобрений. Волгоград: IPNI, 2015. Режим доступа: http://eeca-ru.ipni.net/article/EECARU-2282

5. Филин В.И., Филин В.В. Оптимизация системы удобрения овощных культур в Волгоградской области // Известия Нижневолжского агроуниверситетского комплекса: наука и высшее профессиональное образование. 2011. № 3 (23). С. 43-50.

6. Азарьева И.И. Совершенствование технологии капельного орошения томатов на светлокаштановых почвах Нижнего Поволжья : автореф. дисс. канд. с.-х. наук. Волгоград, 2010. $23 \mathrm{c}$.

7. Бородычев В.В. Современные технологии капельного орошения овощных культур: научное издание. Коломна : ФГНУ ВНИИ «Радуга», 2010. $241 \mathrm{c.}$

8. Комаров В.Н., Киселева Н.Н., Воронщова А.И. Применение технологических приемов возделывания томата при капельном орошении // Мелиорация и проблемы восстановления сельского хозяйства в России: Материалы междунар. научно-практ. Конф. (Костяковские чтения). 2013. С. 163-166.

9. Овчинников А.С., Бочарников В.С., Бочарникова О.В., Мещеряков М.П. Инновационные технологии орошения овощных культур // Известия Нижневолжского агроуниверситетского комплекса: наука и высшее профессиональное образование. 2011. № 4 (24). С. 13-17.

10. Григоров М.С. Продуктивность томатов при капельном орошении в условиях светло-каштановых почв Волгоградской области // Известия Нижневолжского агроуниверситетского комплекса: наука и высшее профессиональное образование. 2014. № 2 (34). С. 22-27.

11. Носов В.В., Плескачев Ю.Н., Филин В.И., Чамурлиев О.Г., Борисенко И.Б., Холод А.А., Сидоров A.Н. Фертигация томата кальций- и хлорсодержащими удобрениями и некорневые подкормки комплексными водорастворимыми удобрениями на светло-каштановой почве Волгоградской области // Питание растений. 2017. № 3. С. 7-12.

12. Филин В.И. Программирование урожая: от идеи к теории и технологиям сельскохозяйственных культур // Известия Нижневолжского агроуниверситетского комплекса: наука и высшее профессиональное образование. 2014. № 3 (35). С. 26-36.

13. Авдеев Ю.И. Технология томатов в открытом грунте Астраханской области // Картофель и овощи. 2014. № 5. С. 7 -9.

14. Гиль Л.С., Пашковский А.И., Сулима Л.Т. Современное овощеводство закрытого и открытого грунта. Практическое руководство. Житомир : Рута, 2012. 468 с. Режим доступа: https://ua.b-ok2.org/book/3037453/300cb0

15. Грушанин А.И., Бут Н.Н. Новые сорта и гибриды томата для открытого грунта Кубани // Картофель и овощи. 2012. № 3. С. 19-20.

\section{About the authors:}

Chamurliev Omariy Georgievich - Doctor of Agricultural Sciences, Professor, Head of the Department of Agriculture and Agrochemistry, Volgograd State Agricultural University, 26, pr. Universitetsky, Volgograd, 400002, Russian Federation; e-mail: attika.ge@yandex.ru

Sidorov Alexander Nikolaevich - Candidate of Agricultural Sciences, senior lecturer, Department of Agriculture and Agrochemistry, Volgograd State Agricultural University, 26, pr. Universitetsky, Volgograd, 400002, Russian Federation; e-mail: sash-ka2008@mail.ru

Kholod Anatoly Aleksandrovich - Candidate of Agricultural Sciences, senior lecturer, Department of Agriculture and Agrochemistry, Volgograd State Agricultural University, 26, pr. Universitetsky, Volgograd, 400002, Russian Federation; e-mail: olodok2009@rambler.ru 
Chamurliev Georgy Omarievich - Candidate of Agricultural Sciences, senior lecturer, Agroengineering Department, Agrarian and Technological Institute, Peoples' Friendship University of Russia, 8, Mikluho-Maklaya st., Moscow, 117198, Russian Federation; e-mail: giorgostsamourlidis@mail.ru

Bogomolova Natalia Vladimirovna - Head of the Laboratory of Experimental Remote Sensing and Monitoring of Land Resources, master student, Agrarian and Technological Institute, 8, MikluhoMaklaya st., Moscow, 117198, Russian Federation; e-mail: bogomolova_nv@pfur.ru

\section{Об авторах:}

Чамурлиев Омарий Георгиевич - доктор сельскохозяйственных наук, профессор, заведующий кафедрой земледелия и агрохимии Волгоградского государственного аграрного университета, 400002, Российская Федереация, г. Волгоград, пр. Университетский, д. 26; е-таil: attika.ge@yandex.ru

Сидоров Александр Николаевич — кандидат сельскохозяйственных наук, старший преподаватель кафедры земледелия и агрохимии Волгоградского государственного аграрного университета, 400002, Российская Федереация, г. Волгоград, пр. Университетский, д. 26; e-mail: sash-ka2008@mail.ru

Холод Анатолий Александрович — кандидат сельскохозяйственных наук, старший преподаватель кафедры земледелия и агрохимии Волгоградского государственного аграрного университета, 400002, Российская Федереация, г. Волгоград, пр. Университетский, д. 26; е-таil: olodok2009@rambler.ru

Чамурлиев Георгий Омариевич - кандидат сельскохозяйственных наук, старший преподаватель агроинженерного департамента Аграрно-технологического института Российского университета дружбы народов, Российская Федерация, 117198, Москва, ул. Миклухо-Маклая, 8; e-mail: giorgostsamourlidis@mail.ru

Богомолова Наталья Владимировна - заведующая лабораторией экспериментального дистанционного зондирования и мониторинга земельных ресурсов, магистрант Аграрно-технологического института Российского университета дружбы народов, Российская Федерация, 117198, Москва, ул. Миклухо-Маклая, 8; e-mail: bogomolova_nv@pfur.ru 